DOI: $10.1002 /(($ please add manuscript number $))$

Article type: Communication

\title{
Amphiphilic Nanofiber Based Aerogels for Selective Liquid Absorption from Electrospun Biopolymers
}

Fabian Deuber, Sara Mousavi, Lukas Federer, and Christian Adlhart*

F. Deuber, S. Mousavi, L. Federer, Dr. C. Adlhart

Institute of Chemistry and Biotechnology, Zurich University of Applied Sciences ZHAW, Einsiedlerstrasse 31, 8820 Wädenswil, Switzerland

S. Mousavi

Department of Chemical Engineering, University of Sistan and Baluchestan, Zahedan, Iran E-mail: christian.adlhart@zhaw.ch

Keywords: aerogels, biopolymers, electrospinning, solid templating, water purification

\begin{abstract}
Hierarchically structured and ultralight pullulan/PVA aerogels or sponges were prepared from short electrospun nanofibers using solid templating. The architecture of the aerogel consisted of cell-like pores of 50 to $100 \mu \mathrm{m}$ interconnected by a network of entangled nanofibers with 2 to $5 \mu \mathrm{m}$ pores. Such structures allow rapid liquid uptake with high liquid holding capacities at the same time. The amphiphilic nature of the aerogel from the electrospun biopolymer was switched by chemical vapor deposition of silane. This allows the selective separation of liquids based on their different relative dielectric constants, which is of high interest for oil spilled waters and produced water. Furthermore, silylation improved the aerogel's overall mechanical stability by $18 \%$ while increasing its density by only $5 \%$. SEM in situ compression studies revealed the importance of the fibrous entanglement and the open-porous architecture for the high bendability and mechanical resilience of the aerogels. Solid templating of short electrospun nanofibers facilitates the design of a fascinating class of ultralight aerogels while prevailing the fibrous character and the versatility of electrospinning.
\end{abstract}




\section{WILEY-VCH}

\section{Introduction}

Electrospinning allows the fabrication of nanofibers from biopolymers, synthetic polymers, and even metals. In terms of applications electrospinning has outperformed alternative technologies for nanofiber production such as melt blowing, ${ }^{[1]}$ self-assembly, ${ }^{[2]}$ phase separation, ${ }^{[3]}$ solution blow spinning, ${ }^{[4]}$ and nanofiber drawing. ${ }^{[3 a]}$ Electrospun nanofibers feature a large specific surface area, ultra-high aspect ratio, extreme flexibility, and the electrospinning process can easily be scaled up. One limitation in electrospinning is the anisotropic lamellar deposition character due to the layer-by-layer manufacturing process. ${ }^{[5]}$ Different ways to fabricate porous 3D structures from electrospun nanofibers have been exploited, ${ }^{[6]}$ such as self-assembly, ${ }^{[7]}$ cool drum spinning ${ }^{[8]}$ or gas expansion. ${ }^{[9]}$ Even though those 3D scaffolds lack the possibility to add scalable pores and often suffer from poor mechanical stability, ${ }^{[10]}$ the scientific resources devoted to developing electrospun $3 \mathrm{D}$ materials are increasing each year. ${ }^{[6]}$ The unique properties of $3 \mathrm{D}$ materials from electrospun nanofibers enable their application as scaffolds in tissue engineering, ${ }^{[11]}$ framework for heterogeneous catalysis, ${ }^{[12]}$ drug release composites, ${ }^{[11 \mathrm{c}, 13]}$ personal safety equipment, ${ }^{[14]}$ sensors, ${ }^{[15]}$ or electrodes. ${ }^{[16]}$

It has been shown recently, that colloidal dispersions of short electrospun nanofibers prepared by cutting electrospun membranes open a complementary and controlled approach in nonwoven nanofiber processing. ${ }^{[17]}$ This change in paradigm — to separate fiber formation and fiber processing - elegantly overcomes the main drawback of electrospinning, since fiber processing is no longer coupled to the intrinsically lamellar fiber deposition, but separated into more versatile liquid handling process. Using short electrospun nanofiber dispersions, Ding ${ }^{[5 \mathrm{a}]}$ and Greiner ${ }^{[18]}$ pioneered the preparation of ultralight 3D aerogels or sponges by freeze casting. These nanofiber based 3D materials are either referred to as aerogels ${ }^{[5 a]}$ or sponges ${ }^{[18]}$. They show high porosities like silica based aerogels, but the solid 


\section{WILEY-VCH}

scaffold is pre-formed by short nanofibers. ${ }^{[19]}$ Our group rigorously controlled this underlying self-assembly solid templating process to form hierarchically structured nanofiber aerogels with tailored pore size. ${ }^{[20]}$

We present a simple and efficient route to prepare highly porous interconnected networks of electrospun nanofibers with tailored pore feature. Furthermore, we illustrate the vast potential of post-treating such 3D aerogels: subsequent hydrophobic modification using chemical vapor deposition (CVD) allowed us to alter the inherent characteristics and morphology of the electrospun pullulan/PVA nanofibers within the aerogel. The nanofiber based aerogels in this work were designed to fulfill several criteria. (i) The 3D framework of the aerogel should not collapse during further treatment and thus had to be mechanically resistant. (ii) The structure should display an open cellular architecture and most importantly (iii) the intrinsic properties and shape of the nanofibers - such as large specific surface area and aspect ratio - were retained. By selecting a pullulan/PVA blend as nanofiber starting material, we were able to perform in situ crosslinking to ensure high mechanical stability and to increase compression resistance. ${ }^{[21]}$ Furthermore, pullulan — a homopolysaccharide of glucose — is biodegradable, GRAS-approved and amphiphilic, because of the presence of hydrophilic hydroxyls groups and hydrophobic pyranose rings. In contrast to the hydrophobic nanofiber aerogels prepared by Ding ${ }^{[5 a, 22]}$ and Greiner, ${ }^{[18,23]}$ the amphiphilic character of pullulan allows the uptake of both polar and non-polar solvents. Additionally, the presence of ample hydroxyl groups facilitates chemical post modification. ${ }^{[2]}$ We meth the remaining two requirements hierarchically structured features and the preservation of the characteristics of the nanofibers by using a controlled solid templating technique adapted for short pullulan/PVA nanofibers.

To synthesize the aerogel, see Figure 1a, nonwoven nanofiber membranes were first produced by environment-friendly free-surface electrospinning pullulan/PVA from aqueous 


\section{WILEY-VCH}

solution (see Supporting Information). Electrospinning under benign conditions yielded uniform nanofibers with a diameter of $240 \pm 55 \mathrm{~nm} \cdot{ }^{[25]}$ The nanofiber membranes were homogenized in 1,4-dioxane to provide a suspension of short nanofibers with a length of approx. $40 \mu \mathrm{m}$, and subsequently frozen using a directional solid templating approach. ${ }^{[20,26]}$ Sublimation by freeze-drying yielded the green bodies — an ultralight (density between 4.1 and $48.2 \mathrm{mg} \mathrm{ml}^{-1}$ ) and highly porous (porosity up to $99.7 \%$ ) fibrous network with directional pores along the thermal freezing gradient. It is so light that a dandelion can carry it without deforming the fluffy seed heads (Figure1b). By carefully controlling both the fiber concentration and the freezing conditions, solid templating showed great flexibility in tailoring both the microstructure and the macrostructure of the architecture of the aerogel (see Supporting Information). The water soluble green bodies were thermally crosslinked at $180{ }^{\circ} \mathrm{C}$ for $40 \mathrm{~min}$ to render them insoluble. During this thermal process, at least two reactions occur simultaneously: first ether bond formation, which renders the polymers water insoluble, and second carbohydrate oxidation (caramelization) of maltose, a residue from the pullulan production, leaving a brownish hue. Crosslinking of the pullulan/PVA green bodies increased the compressibility and mechanical resistance, but lead to a shrinking between 45 and $65 \%$,

Table 1. Crosslinking the water-soluble pullulan/PVA polymer blend is crucial for its application under wet conditions and outweighs the side-effects (shrinking and discoloration) during the thermal crosslinking of the aerogel. Adding supporting inorganic nanofibers such as $\mathrm{SiO}_{2}$ can preserve the initial volume during thermal crosslinking at the cost of the biodegradable properties of the aerogels. ${ }^{[5 a, 22]}$ Likewise, using polymeric or inorganic coatings to enhance the stability of the aerogels leads to a loss of the intrinsic surface properties of the fibers. ${ }^{[23]}$ 
WILEY-VCH

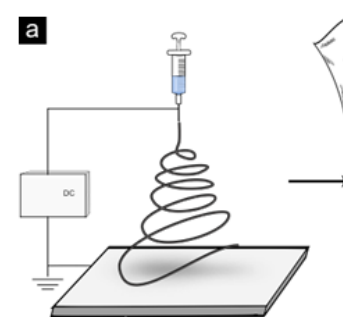

1. Electrospinning

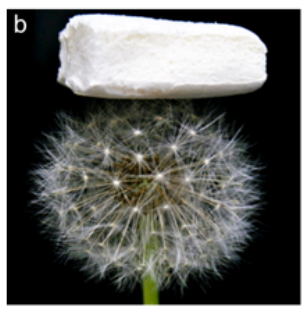

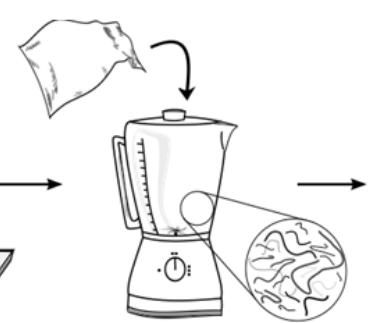

2. Homogenizing

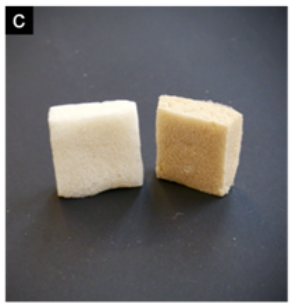

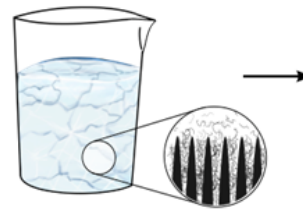

3. Solid templating and freeze drying
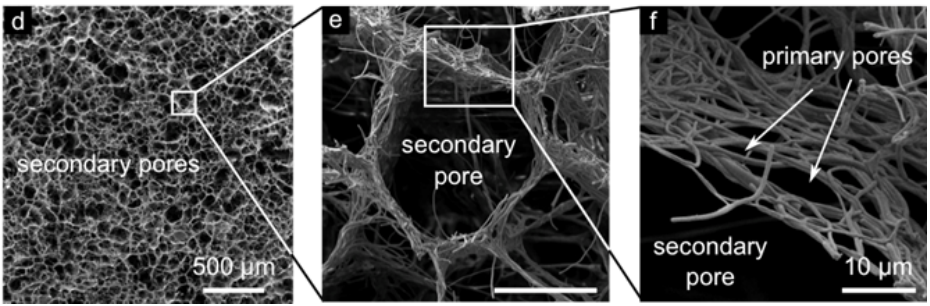

Figure 1. a) Processing steps for the synthesis of 3D electrospun nanofiber based aerogels by freeze-casting: 1.) electrospinning uniform nanofibers, 2.) homogenizing of the electrospun membrane in a wetting non-dissolving liquid to obtain short fibers with a length of approx. 40 $\mu \mathrm{m}$ and an aspect ratio of $120-150,3$.) solid templating at a controlled rate and successive sublimation of the solidified non-solvent to obtain the free standing green body aerogel, 4.) thermal crosslinking to achieve water insolubility, 5.) hydrophobic modification of the amphiphilic network by CVD with trichloro(octyl)silane (TOS). b) Pullulan/PVA aerogel (apparent density of $8.7 \mathrm{mg} \mathrm{ml}^{-1}$ ) freestanding on a dandelion without deforming the fluffy seed heads. c) Discoloration associated with crosslinking (left) and post-treatment (right) of the nanofiber aerogel. d) to f) SEM images of a cross-section from a nanofiber-based aerogel perpendicular to the freezing direction showing the hierarchical pore architecture at different magnification. The open pore architecture with major secondary pores between $50-100 \mu \mathrm{m}(\mathrm{d}$ and e) and minor primary pores between $2-5 \mu \mathrm{m}$ (e) is clearly visible. Notably, the nanofibers' morphology within the aerogel is preserved.

We could modify the amphiphilic framework of the aerogel to selectively absorb non-polar liquids by CVD using trichloro(octyl)silane (TOS). Chemical vapor deposition proved to be an easy but efficient means to render the surface of the fiber hydrophobic without altering the pore structure of the aerogel. The increase in density was only $5 \%$, regardless of the density of the aerogel before TOS treatment. A slight change in color was observed, see Figure 1c.

Table 1. Archimedean densities of the green body, the crosslinked aerogel, and the post modified silylated aerogel, their Archimedean porosities, and associated volume shrinkage during crosslinking.

\begin{tabular}{|c|c|c|c|c|c|c|}
\hline $\begin{array}{l}\text { Density } \\
\text { Green } \\
\text { body [mg } \\
\mathrm{ml}^{-1} \text { ] }\end{array}$ & $\begin{array}{l}\text { Porosity } \\
\text { Green body } \\
{[\%]^{a)}}\end{array}$ & $\begin{array}{c}\text { Density } \\
\text { Crosslinked } \\
{\left[\mathrm{mg} \mathrm{ml}^{-1}\right]}\end{array}$ & $\begin{array}{l}\text { Porosity } \\
\text { Crosslinked } \\
\left.[\%]^{a}\right)^{2}\end{array}$ & $\begin{array}{c}\text { Volume } \\
\text { Shrinkage } \\
{[\%]}\end{array}$ & $\begin{array}{l}\text { Density } \\
\text { Silylated } \\
{\left[\mathrm{mg} \mathrm{ml}^{-1}\right]}\end{array}$ & $\begin{array}{c}\text { Porosity } \\
\text { Silylated } \\
{[\%]^{\text {a) }}}\end{array}$ \\
\hline 4.13 & 99.72 & 11.88 & 99.18 & 65.2 & 12.64 & 99.13 \\
\hline
\end{tabular}


WILEY-VCH

\begin{tabular}{lllllll}
8.78 & 99.40 & 23.20 & 98.40 & 62.2 & 24.64 & 98.31 \\
18.62 & 98.72 & 48.91 & 96.64 & 61.9 & 50.84 & 96.50 \\
48.21 & 96.68 & 88.52 & 93.91 & 45.6 & 92.27 & 93.65 \\
\hline
\end{tabular}

${ }^{\text {a) }}$ For calculating the porosity see the Supporting Information.

The pore formation process during solid templating is understood by the accepted freezing mechanism for nanoparticle slurries, ${ }^{[27]}$ where the dispersed nanofibers are rejected by the moving solidification front of the growing solvent crystals and thus concentrate between the crystals to form walls of entangled nanofibers separating cellular pores. We could demonstrate that the pore size and shape could be tailored by influencing either the freezing front velocity during freezing or by adjusting the slurry's viscosity through changing the fiber fraction. ${ }^{[5 \mathrm{a}, 20,22 \mathrm{~b}]}$ The architecture of the aerogels reveals hierarchical pores: minor primary pores between tangled nanofibers and major cell-like secondary pores. This hierarchical nanostructure and microstructure is clearly visible in SEM images of aerogel cross sections, see Figure 1d to Figure 1e. By zooming in on a major secondary pore, minor primary pores with a size of 2-5 $\mu \mathrm{m}$ are distinctly visible. These primary pores are about the same size as those in electrospun membranes. ${ }^{[15 b, 28]}$ A significant difference between these nanofiber based aerogels and conventional cellulose aerogels is the preserved fibrous character within the cell walls despite their ultra-thin dimensions. Typical cellulose aerogels have smooth, regular pore walls, so they are not truly interconnected. ${ }^{[24]}$ Whereas here, the primary pores are interconnected with the larger, secondary pores yielding a truly interconnected, open-pore network of nanofibers. Investigating the sponges with respect to the freezing direction reveals that the secondary pores were aligned parallel to the thermal freezing gradient, see Figure S3. Hence, the aerogel has a hierarchical anisotropic architecture. Such anisotropic properties have been reported many times for ice templated ceramics - both in terms of structure such as strength and $E$-modulus, but also in terms of function such as thermal conductivity, acoustic properties, or gas permeability. ${ }^{[29]}$ Here, we were interested in thehierarchical pores for 


\section{WILEY-VCH}

efficient mass transport properties in combination with a large and accessible internal surface provided by the network of entangled nanofibers.

The combination of the robust hierarchical cellular structure and the characteristic entanglement of the fibers may also be responsible for the high bendability and reversible compressibility of the nanofiber aerogels. They are superior to the typically fragile ceramic aerogels, which disintegrate under compression stress. ${ }^{[30]}$ By studying their compression behavior, we found that the aerogels can bear high compression strain, $\varepsilon$, up to $80 \%$ and still recover their original shape. Stress-strain curves display two characteristic regimes: a linear, Hookean regime for $\varepsilon \leq 40 \%$, where no plastic deformation occurs, and a densification regime above $\varepsilon \geq 40 \%$, see Figure 2a. Deformation was also observed by SEM in situ compression studies, where the pore walls undergo non-linear compression at high deformation, also known as elastic buckling. ${ }^{[31]}$ We carried out multiple compression cycles, see Figure 2c, and observed a plastic deformation of the structure after the first five compression cycles at a strain of $\varepsilon=60 \%$. However, it is less pronounced for the silylated aerogel, emphasizing the reinforcement through silylation. At reduced compression strain of $\varepsilon=30 \%$ the aerogels exhibited almost no deformation and retained their original shape even after 100 cycles, see Figure S6c. The rapid shape recovery of the ultralight aerogel is also observed when wet (see Figure S7). Whereas conventional open-porous foams display failure and plastic deformation due to exhaustive buckling, fibrous aerogel display fatigue residency. Due to the fibrous structure in the pore walls of the aerogels fast energy dispersion throughout the entire structure is ensured. This so-called multi-arch architecture acts as an elastic springtype cushioning system, minimizing the effect of fatigue failure ${ }^{[32]}$ This efficient load transfer was observed when studying the open porous aerogel by in situ scanning electron microscopy (SEM), see Figure 2e and $\mathrm{f}$. 


\section{WILEY-VCH}

Youngs' moduli were between 5.1 and $401 \mathrm{kPa}$ depending on the density of the silylated aerogel (from 12.64 to $92.27 \mathrm{mg} \mathrm{ml}^{-1}$ ). While crosslinking and successive silylation of the aerogel renders the structure non-soluble and hydrophobic, the $E$-modulus depends primarily on the density of the aerogel. Normalized to their density the specific $E$-moduli of the aerogels were within 0.45 and $4.2 \mathrm{MPa} \mathrm{ml} \mathrm{g}^{-1}$, thus they are comparable with other solid templated aerogels from electrospun nanofibers. ${ }^{[5 \mathrm{a}, 18,22 \mathrm{a}, 23,33]}$ Thanks to their highly interconnected fibrous network they exhibit similar properties as carbohydrate aerogels with smooth regular pore walls from cellulose $\left(<2 \mathrm{MPa} \mathrm{ml} \mathrm{g}^{-1}\right),{ }^{[34]}$ or $\left.\operatorname{starch}(<10 \mathrm{MPa} \mathrm{ml} \mathrm{g})^{-1}\right){ }^{[35]}$ Carbon aerogels, however, generally show higher specific $E$-moduli (20 MPa ml g ${ }^{-1},{ }^{[36]}$ or even over $330 \mathrm{MPa} \mathrm{ml}{ }^{-1}{ }^{[37]}$ ) thus suggesting that pyrolysis of the pullulan/PVA aerogel could potentially improve mechanical properties. Using the model proposed by Gibson and Ashby the architecture of a cellular material can be elucidated, given its scaling behavior of the relative $E$-modulus versus its relative density. ${ }^{[31,38]}$ When comparing our aerogel structures with selected materials from literature, it becomes apparent that our aerogels behave like open-cell structures, see Figure $2 \mathrm{~d}$. Our finding confirms the hypothesis of Ding et al. ${ }^{[5 \mathrm{a}, 22 \mathrm{~b}]}$ and is supported by the SEM in situ compression study. 
WILEY-VCH
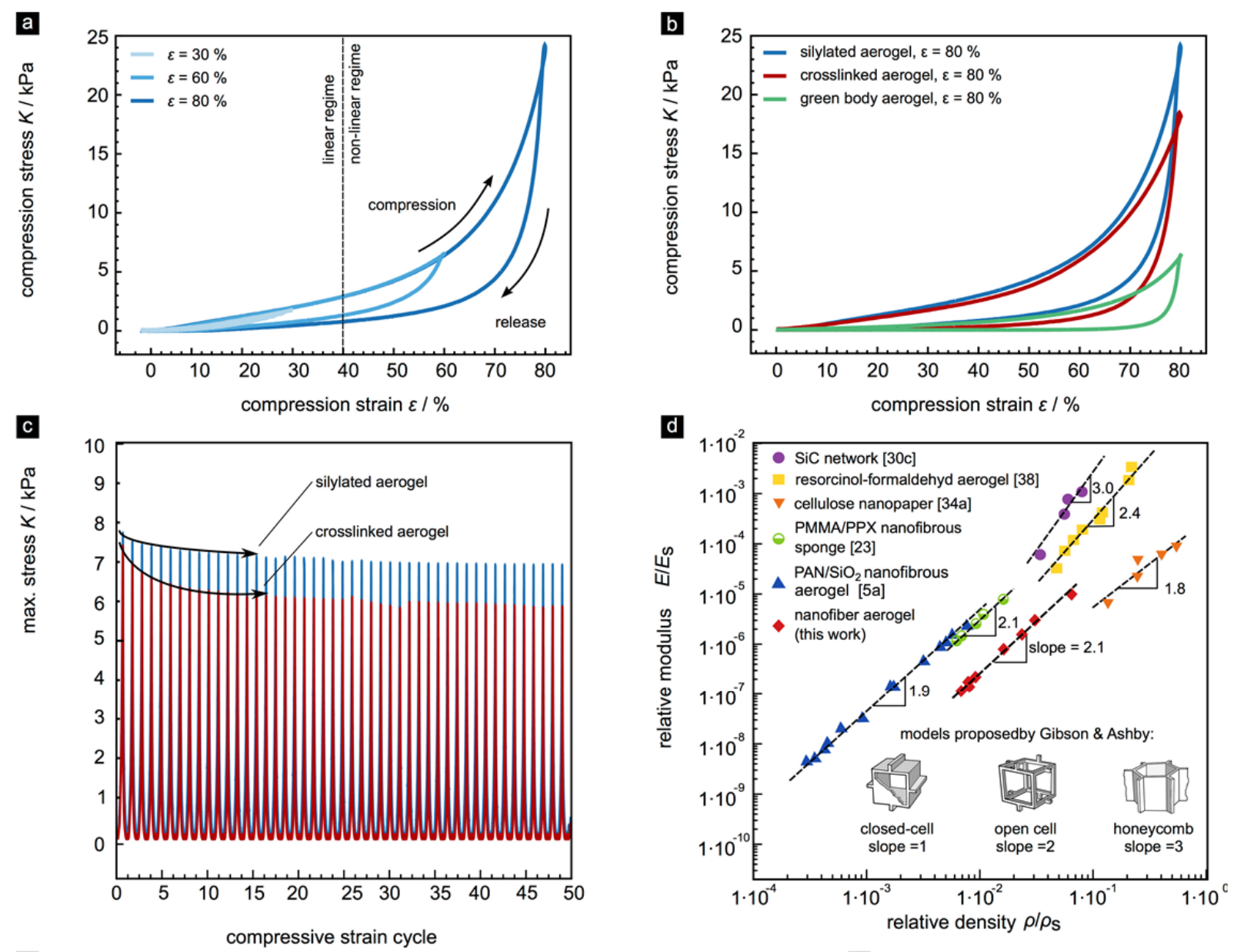

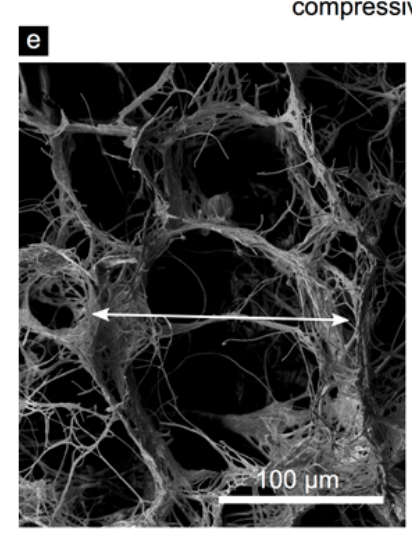

$\varepsilon=0 \%$

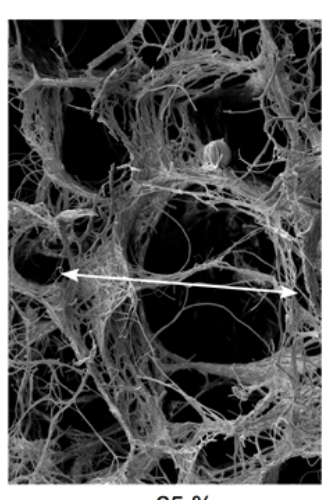

$\varepsilon=25 \%$

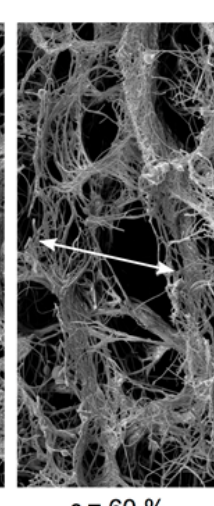

$\varepsilon=60 \%$

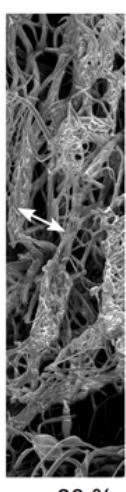

$\varepsilon=80 \%$ f

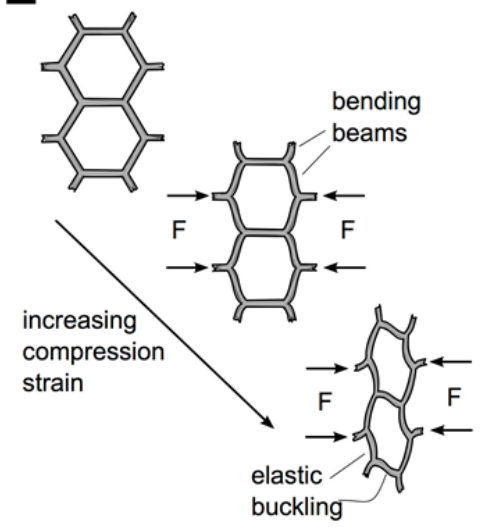

Figure 2. Mechanical properties of the nanofiber based aerogels (green body, crosslinked, and silylated) with an apparent density of $8.78,23.20$, and $24.64 \mathrm{mg} \mathrm{ml}^{-1}$, respectively (Table 1).

a) Compression stress, $K$, versus compression strain $\varepsilon=30,60$ and $80 \%$ of the silylated aerogel. b) Comparison of the compression behavior of the aerogel after different processing steps (green body, crosslinked, and silylated). c) First 50 cycles of the fatigue test at a compression strain $\varepsilon=60 \%$ illustrating the enforcement by silylation (for 100 cycles see Figure S6). d) Scaling behavior of nanofiber based aerogels with different densities. Literature data: ${ }^{[5 a, 23,30 c, 34 a, 39]}$ The nanofiber based aerogels from this work show open-cell behavior (slope 2.1). $E_{\mathrm{s}}$ and density $\rho_{\mathrm{s}}$ of the solid were estimated using literature values of pullulan $^{[40]}$ and PVA: ${ }^{[41]} E_{\text {pullulan }}=28 \mathrm{GPa}, \rho_{\text {pullulan }}=1.85 \mathrm{mg} \mathrm{ml}^{-1}$ and $E_{\mathrm{PVA}}=46 \mathrm{GPa}, \rho_{\mathrm{PVA}}$ $=1.19 \mathrm{mg} \mathrm{ml}^{-1}$, respectively. The pullulan/PVA ratio to calculate the weighted arithmetic mean E-modulus and density of the composite was2:3. e) SEM in situ compression study with 


\section{WILEY-VCH}

increasing degree of compression (parallel to the freezing direction). The proposed elastic buckling can be observed by following the pore walls of the secondary pores (white arrow). f) Mechanistic scheme for the compression of open-pore structures.

With hydroxyl groups surrounding the hydrophobic pyranose ring, pullulan exhibits similarly to cellulose an affinity to both polar and non-polar solvents. Unmodified but crosslinked pullulan/PVA aerogels with a density of $11.88 \mathrm{mg} \mathrm{ml}^{-1}$ absorb due to their amphiphilic nature both water $\left(102.0 \mathrm{~m}^{3} \mathrm{~m}^{-3}\right)$ and chloroform $\left(115.2 \mathrm{~m}^{3} \mathrm{~m}^{-3}\right)$, see Figure 3e. The high liquid absorption capacity, $\varphi$, concerning the fiber volume, indicates a pore filling mechanism via capillary forces, capable of invading up to $100 \%$ of the available free space (total pore volume of $\left.115.6 \mathrm{~m}^{3} \mathrm{~m}^{-3}\right)$. After silylation, water can no longer penetrate but is forming droplets on the aerogel's surface with a contact angle of $136^{\circ}$ (Figure 3b). When a water drop is touching the hydrophobic surface of the aerogel, it is partially penetrating into the hierarchically structured fibrous topography, allowing the small water drops ( $5 \mu 1)$ to adhere to the surface. As shown in Figure 3c, these little water droplets (dyed with methyl blue) do not move - even when rotated upside down — implying the formation of a Cassie impregnating wetting area or a so-called "Gecko"-state. ${ }^{[24 \mathrm{~d}, 42]}$ Simultaneously, hydrophobic silylated pullulan/PVA aerogels rapidly and selectively remove non-polar solvents such as cyclohexane or chloroform from water (Figure 3d and Figure S8). The complete absorption of hydrocarbons from water demonstrates the excellent potential for oil removal, e.g. from produced water. Furthermore, the silylated aerogels display high absorption capacities, $\varphi$, towards a wide range of liquids, including aliphatic (cyclohexane, petroleum ether, $n$ hexadecane), polar aprotic (ethyl acetate, 1,4-dioxane), chlorinated (dichloromethane, chloroform) solvents, and silicone oil. When the hydrophobic aerogel is forced into polar solvents such as water, ethylene glycol or dimethyl sulfoxide (DMSO) the liquid is repelled, filling only less than $15 \%$ of the available pore volume. Hence, it is evident, that a higher relative dielectric constant $\varepsilon_{\mathrm{r}}$ of a solvent with $\varepsilon_{\mathrm{r}} \geq 37$ correlates with less or no absorption 


\section{WILEY-VCH}

capacity. By further exploiting the high and tunable porosity of such electrospun nanofiber based aerogels, it is even possible to increase the absorption capacity to almost $430 \mathrm{~m}^{3} \mathrm{~m}^{-3}$. ${ }^{[18]}$

In summary ultralight $\left(4.13 \mathrm{mg} \mathrm{ml}^{-1}\right)$ and highly porous $(99.70 \%)$ nanofiber based aerogels were successfully synthesized using a controlled solid templating approach for short electrospun nanofibers. CVD with TOS was applied to turn the initially amphiphilic pullulan/PVA framework of the aerogel into a hydrophobic one with selective absorption of non-polar solvents. This illustrates the potential of combining two established high impact techniques namely electrospinning and freeze-casting. We expect that thanks to their outstanding mechanical behavior, their large specific surface area, and their tunable microstructure these fascinating nanofiber based aerogels obtained by solid templating will establish in numerous applications: either as filtration and separator structure, as a catalyst support, as dampers and isolators, as pressure sensors, absorbents, or as a scaffold for tissue engineering. 


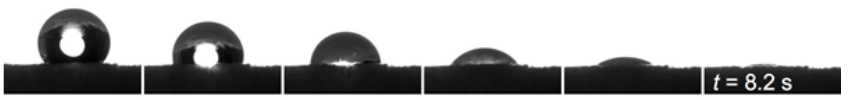

b silylated aerogel
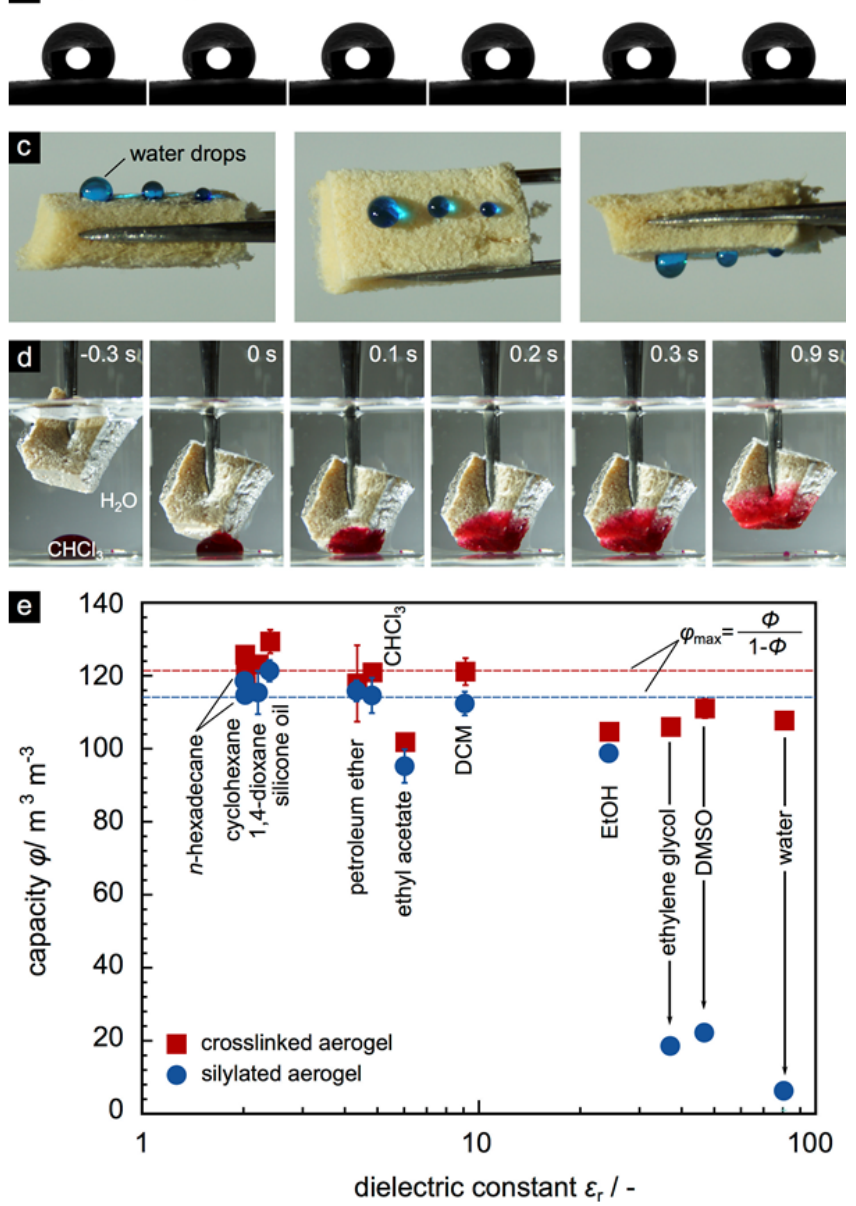

Figure 3. a) Dynamic water absorption of the amphiphilic crosslinked pullulan/PVA aerogel. b) The water contact angle of the hydrophobic silylated aerogel remained at $136^{\circ}$. c) Demonstration of water adhesion on the silylated aerogel by rotation from 0 to 180 degrees. d) Rapid and selective uptake of a non-polar liquid (chloroform, dyed with Sudan red IV) from water through the silylated aerogel with full absorption within $0.3 \mathrm{~s}$. e) Absorption capacity $\varphi=V_{\text {liquid }} / V_{\text {fiber }}$ of amphiphilic crosslinked and silylated pullulan/PVA aerogels with apparent density of 11.88 , and $12.64 \mathrm{mg} \mathrm{ml}^{-1}$, respectively (Table 1). The dashed lines represent the maximum absorption capacity, $\varphi_{\max }$, assuming $100 \%$ pore filling

\section{Experimental Section}

Preparation of pullulan/PVA aerogels: The Pullulan/PVA composite nanofibers were prepared by dissolving $4 \mathrm{~g}$ Pullulan (food grade, Hayashibara co. Ltd, Japane) and $6 \mathrm{~g}$ PVA $(\mathrm{Mw}=89000-98000 \mathrm{Da}, \mathrm{DH}=99 \%$, Sigma-Aldrich $)$ in $90 \mathrm{~g}$ Water. Electrospun nanofiber membranes were obtained by free liquid surface electrospinning with a Nanospider ${ }^{\mathrm{TM}}$ NS lab 500 from Elmarco. The fibers were spun at a high voltage of $80 \mathrm{kV}$ using a cylindrical electrode and a collector distance of $16 \mathrm{~cm}$. Temperature and relative humidity during 


\section{WILEY-VCH}

electrospinning were $26 \pm 3{ }^{\circ} \mathrm{C}$ and $26 \pm 4 \%$, respectively. In a typical experiment for the fabrication of nanofiber based aerogels with an apparent density of $8.78 \mathrm{mg} \mathrm{ml}^{-1}$, the nanofiber membrane was cut into small pieces of approx. $1 \times 1 \mathrm{~cm}^{2}$ and dispersed in $100 \mathrm{ml}$ 1,4-dioxane by an IKA T25 homogenizer for $20 \mathrm{~min}$ at $13000 \mathrm{rpm}$. The homogenous dispersion was subsequently poured into a mold and frozen at a specific rate (here $10.29 \mu \mathrm{m} \mathrm{s}^{-}$

$\left.{ }^{1}\right)$. The frozen solid was then freeze-dried for $48 \mathrm{~h}$ and finally thermally crosslinked at a temperature of $180^{\circ} \mathrm{C}$ for $40 \mathrm{~min}$. To obtain hydrophobically modified aerogels by chemical vapor deposition using TOS (purity $=97 \%$, Sigma-Aldrich), a glass container containing TOS was placed together with the crosslinked pullulan/PVA aerogel in a closed desiccator. After $24 \mathrm{~h}$ of reaction time at ambient temperature, the surface modified aerogel was subsequently placed under vacuum (10 mbar, 2 hours) to eliminate the excess silane and the coupling product $\mathrm{HCl}$.

\section{Supporting Information}

Supporting Information providing details on the electrospinning process, the solid templating conditions, thermal crosslinking, and physical chemical characterization of the aerogels is available from the Wiley Online Library or from the authors.

\section{Acknowledgements}

This work was supported by Forschungsfond Aargau, IVF-Hartmann AG (Thesis of F. D.), and COST ACTION MP1206 (travelling grants).

Received: ((will be filled in by the editorial staff))

Revised: ((will be filled in by the editorial staff)) Published online: ((will be filled in by the editorial staff))

\section{References}

[1] M. A. Hassan, B. Y. Yeom, A. Wilkie, B. Pourdeyhimi, S. A. Khan, J. Membr. Sci. 2013, 427, 336.

[2] J. D. Hartgerink, E. Beniash, S. I. Stupp, Science 2001, 294, 1684.

[3] a) Y. Z. Zhang, C. T. Lim, S. Ramakrishna, Z. M. Huang, J. Mater. Sci. - Mater. Med. 2005, 16, 933; b) F. Yang, R. Murugan, S. Ramakrishna, X. Wang, Y. X. Ma, S. Wang, Biomaterials 2004, 25, 1891. 


\section{WILEY-VCH}

[4] a) E. S. Medeiros, G. M. Glenn, A. P. Klamczynski, W. J. Orts, L. H. C. Mattoso, J. Appl. Polym. Sci. 2009, 113, 2322; b) A. M. Behrens, B. J. Casey, M. J. Sikorski, K. L. Wu, W. Tutak, A. D. Sandler, P. Kofinas, ACS Macro Lett. 2014, 3, 249.

[5] a) Y. Si, J. Yu, X. Tang, J. Ge, B. Ding, Nat. Commun. 2014, 5, 5802; b) W. E. Teo, S. Ramakrishna, Nanotechnology 2006, 17, R89; c) J. H. Wendorff, S. Agarwal, A. Greiner, Electrospinning: Materials, Processing, and Applications, Wiley-VCH, Weinheim, 2012; d) A. Greiner, J. H. Wendorff, Angew. Chem. Int. Ed. 2007, 46, 5670; e) R. Buttiker, J. Ebert, C. Hinderling, C. Adlhart, Chimia 2011, 65, 182.

[6] a) B. Sun, Y. Z. Long, H. D. Zhang, M. M. Li, J. L. Duvail, X. Y. Jiang, H. L. Yin, Prog. Polym. Sci. 2014, 39, 862; b) B. Sun, X.-J. Jiang, S. Zhang, J.-C. Zhang, Y.-F. Li, Q.-Z. You, Y.-Z. Long, J. Mater. Chem. B 2015, 3, 5389.

[7] a) B. Sun, Y.-Z. Long, F. Yu, M.-M. Li, H.-D. Zhang, W.-J. Li, T.-X. Xu, Nanoscale 2012, 4, 2134; b) X. Guo, Y. Yao, T. Zhou, R. Xiang, M. Chen, J. Appl. Polym. Sci. 2015, 133, 43003; c) G. Chang, X. Zhu, A. Li, W. Kan, R. Warren, R. Zhao, X. Wang, G. Xue, J. Shen, L. Lin, Mater. Des. 2016, 97, 126.

[8] M. Simonet, O. D. Schneider, P. Neuenschwander, W. J. Stark, Polym. Eng. Sci. 2007, 47, 2020.

[9] J. Jiang, M. A. Carlson, M. J. Teusink, H. Wang, M. R. MacEwan, J. Xie, ACS Biomater. Sci. Eng. 2015, 1, 991.

[10] J. Rnjak-Kovacina, A. S. Weiss, Tissue Eng., Part B 2011, 17, 365.

[11] a) H. Yoshimoto, Y. M. Shin, H. Terai, J. P. Vacanti, Biomaterials 2003, 24, 2077; b) W. J. Li, C. T. Laurencin, E. J. Caterson, R. S. Tuan, F. K. Ko, J. Biomed. Mater. Res. 2002, 60, 613; c) M. Goldberg, R. Langer, X. Jia, J. Biomater. Sci., Polym. Ed. 2007, 18, 241; d) S. Agarwal, J. H. Wendorff, A. Greiner, Polymer 2008, 49, 5603.

[12] a) X. Lu, C. Wang, Y. Wei, Small 2009, 5, 2349; b) E. Formo, E. Lee, D. Campbell, Y. N. Xia, Nano Lett. 2008, 8, 668; c) G. F. J. Müller, M. Stürzel, R. Mülhaupt, Adv. Funct. Mater. 2014, 24, 2860.

[13] T. J. Sill, H. A. von Recum, Biomaterials 2008, 29, 1989.

[14] a) R. Gopal, S. Kaur, Z. Ma, C. Chan, S. Ramarishna, T. Matsuura, J. Membr. Sci. 2006, 281, 581; b) R. S. Barhate, S. Ramakrishna, J. Membr. Sci. 2007, 296, 1.

[15] a) X. Y. Wang, C. Drew, S. H. Lee, K. J. Senecal, J. Kumar, L. A. Sarnuelson, Nano Lett. 2002, 2, 1273; b) Z.-M. Huang, Y. Z. Zhang, M. Kotaki, S. Ramakrishna, Compos. Sci. Technol. 2003, 63, 2223; c) D. Li, Y. L. Wang, Y. N. Xia, Adv. Mater. 2004, 16, 361.

[16] a) V. Thavasi, G. Singh, S. Ramakrishna, Energy Environ. Sci. 2008, 1, 205; b) X. Chen, S. Xu, N. Yao, Y. Shi, Nano Lett. 2010, 10, 2133; c) H. Wu, L. Hu, M. W. Rowell, D. Kong, J. J. Cha, J. R. McDonough, J. Zhu, Y. Yang, M. D. McGehee, Y. Cui, Nano Lett. 2010, 10, 4242.

[17] a) J. S. Kim, D. H. Reneker, Polym. Compos. 1999, 20, 124; b) M. Thieme, S. Agarwal, J. H. Wendorff, A. Greiner, Polym. Adv. Technol. 2009, n/a; c) S. Jiang, G. Duan, J. Schöbel, S. Agarwal, A. Greiner, Compos. Sci. Technol. 2013, 88, 57; d) M. Langner, A. Greiner, Macromol. Rapid Commun. 2016, 37, 351.

[18] G. Duan, S. Jiang, V. Jérôme, J. H. Wendorff, A. Fathi, J. Uhm, V. Altstädt, M. Herling, J. Breu, R. Freitag, S. Agarwal, A. Greiner, Adv. Funct. Mater. 2015, 25, 2850.

[19] S. Jiang, G. Duan, U. Kuhn, M. Morl, V. Altstadt, A. L. Yarin, A. Greiner, Angew Chem Int Ed Engl 2017, 56, 3285.

[20] F. Deuber, S. Mousavi, M. Hofer, C. Adlhart, ChemistrySelect 2016, 1, 5595.

[21] S. Islam, S. Rahaman, J. H. Yeum, Carbohydr. Polym. 2015, 115, 69.

[22] a) Y. Si, Q. Fu, X. Wang, J. Zhu, J. Yu, G. Sun, B. Ding, ACS Nano 2015, 9, 3791; b) Y. Si, X. Wang, C. Yan, L. Yang, J. Yu, B. Ding, Adv. Mater. 2016, 28, 9512. 


\section{WILEY-VCH}

[23] G. Duan, S. Jiang, T. Moss, S. Agarwal, A. Greiner, Polym. Chem. 2016, 7, 2759.

[24] a) F. Jiang, Y.-L. Hsieh, J. Mater. Chem. A 2014, 2, 6337; b) X. Yao, W. Yu, X. Xu, F. Chen, Q. Fu, Nanoscale 2015, 7, 3959; c) R. Lin, A. Li, T. Zheng, L. Lu, Y. Cao, RSC $A d v$. 2015, 5, 82027; d) H. Zhang, Y. Li, Y. Xu, Z. Lu, L. Chen, L. Huang, M. Fan, Phys. Chem. Chem. Phys. 2016, 18, 28297; e) Q. Liao, X. Su, W. Zhu, W. Hua, Z. Qian, L. Liu, J. Yao, RSC Adv. 2016, 6, 63773.

[25] F. Deuber, C. Adlhart, NART 2015-Nanofibers, Applications and Related Technologies 2015, 29.

[26] a) Y. F. Tang, K. Zhao, J. Q. Wei, Y. S. Qin, J. Eur. Ceram. Soc. 2010, 30, 1963; b) L. Hu, C.-A. Wang, Y. Huang, C. Sun, S. Lu, Z. Hu, J. Eur. Ceram. Soc. 2010, 30, 3389; c) T. Fukasawa, Z. Y. Deng, M. Ando, T. Ohji, S. Kanzaki, J. Am. Ceram. Soc. 2002, $85,2151$.

[27] a) T. Fukasawa, Z. Y. Deng, M. Ando, T. Ohji, Y. Goto, J. Mater. Sci. 2001, 36, 2523; b) K. Araki, J. W. Halloran, J. Am. Ceram. Soc. 2005, 88, 1108; c) N. O. Shanti, K. Araki, J. W. Halloran, J. Am. Ceram. Soc. 2006, 89, 2444; d) S. Deville, E. Saiz, R. K. Nalla, A. P. Tomsia, Science 2006, 311, 515; e) S. Deville, Adv. Eng. Mater. 2008, 10, 155; f) W. L. Li, K. Lu, J. Y. Walz, Int. Mater. Rev. 2013, 57, 37; g) Y. Zhou, S. Fu, Y. Pu, S. Pan, A. J. Ragauskas, Carbohydr. Polym. 2014, 112, 277.

[28] D. Li, M. W. Frey, Y. L. Joo, J. Membr. Sci. 2006, 286, 104.

[29] a) S. Deville, Freezing Colloids: Observations, Principles, Control, and Use, Springer, Cham, Switzerland, 2017; b) J. Seuba, S. Deville, C. Guizard, Sci. Technol. Adv. Mat. 2016, accepted manuscript.

[30] a) N. Kranzlin, M. Niederberger, Adv. Mater. 2013, 25, 5599; b) X. Y. Zheng, H. Lee, T. H. Weisgraber, M. Shusteff, J. DeOtte, E. B. Duoss, J. D. Kuntz, M. M. Biener, Q. Ge, J. A. Jackson, S. O. Kucheyev, N. X. Fang, C. M. Spadaccini, Science 2014, 344, 1373; c) C. Ferraro, E. Garcia-Tuñon, V. G. Rocha, S. Barg, M. D. Fariñas, T. E. G. Alvarez-Arenas, G. Sernicola, F. Giuliani, E. Saiz, Adv. Funct. Mater. 2016, 26, 1636; d) J. Seuba, S. Deville, C. Guizard, A. J. Stevenson, Sci. Rep. 2016, 6, 24326.

[31] M. F. Ashby, R. F. M. Medalist, Metall. Trans. A 1983, 14, 1755.

[32] H. L. Gao, Y. B. Zhu, L. B. Mao, F. C. Wang, X. S. Luo, Y. Y. Liu, Y. Lu, Z. Pan, J. Ge, W. Shen, Y. R. Zheng, L. Xu, L. J. Wang, W. H. Xu, H. A. Wu, S. H. Yu, Nat. Commun. 2016, 7, 12920.

[33] a) W. Chen, J. Ma, L. Zhu, Y. Morsi, H. Ei-Hamshary, S. S. Al-Deyab, X. Mo, Colloids Surf., B 2016, 142, 165; b) W. Chen, S. Chen, Y. Morsi, H. El-Hamshary, M. El-Newhy, C. Fan, X. Mo, ACS Appl. Mater. Interfaces 2016, 8, 24415.

[34] a) H. Sehaqui, Q. Zhou, O. Ikkala, L. A. Berglund, Biomacromolecules 2011, 12, 3638; b) C. Wang, Y. Xiong, B. Fan, Q. Yao, H. Wang, C. Jin, Q. Sun, Sci. Rep. 2016, 6,32383 .

[35] a) J. Li, T. Ye, B. Zhou, B. Li, $R S C A d v$. 2014, 4, 22251; b) Z. Y. Wu, C. Li, H. W. Liang, J. F. Chen, S. H. Yu, Angew. Chem. Int. Ed. 2013, 52, 2925.

[36] Y.-Q. Li, Y. A. Samad, K. Polychronopoulou, K. Liao, ACS Sustainable Chem. Eng. 2015, 3, 1419.

[37] H. Huang, P. Chen, X. Zhang, Y. Lu, W. Zhan, Small 2013, 9, 1397.

[38] L. J. Gibson, Mater. Sci. Eng., A 1989, 110, 1.

[39] R. W. Pekala, C. T. Alviso, J. D. Lemay, J. Non-Cryst. Solids 1990, 125, 67.

[40] T. Diab, C. G. Biliaderis, D. Gerasopoulos, E. Sfakiotakis, J. Sci. Food Agric. 2001, 81,988 .

[41] T. Peijs, R. J. M. van Vught, L. E. Govaert, Composites 1995, 26, 83.

[42] a) S. Wang, L. Jiang, Adv. Mater. 2007, 19, 3423; b) A. K. Kota, Y. Li, J. M. Mabry, A. Tuteja, Adv. Mater. 2012, 24, 5838. 
WILEY-VCH 


\section{WILEY-VCH}

Solid templating is the gate to the world of hierarchically structured nanofiber based aerogels. These ultralight pullulan/PVA based materials rapidly absorb the 100 fold amount of liquid thanks to their highly porous architecture. The amphiphilic absorption characteristics were tuned for the selective removal of non-polar liquids from water by post surface modification.

\section{Keyword}

aerogels, biopolymers, electrospinning, soild templating, water purification

F. Deuber, S. Mousavi, L. Federer, Dr. C. Adlhart*

Amphiphilic Nanofiber Based Aerogels for Selective Liquid Absorption from Electrospun Biopolymers

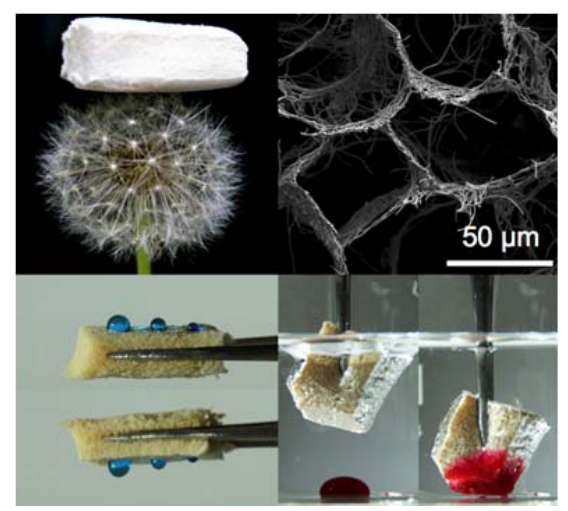

